\title{
Research on the Applications of Multimedia and Network Resources on the Higher Vocational English Teaching
}

\author{
Wei LII, a \\ ${ }^{1}$ Tianjin Light Industry Vocational Technical College, Tianjin 300350, China \\ a mary112000@126.com
}

Keywords: Multimedia Network; Higher Vocational English Teaching; Internet Technology.

\begin{abstract}
With the rapid development of multimedia and English teaching theory, the combination of the two methods is well appreciated recently. In this paper, we research on the applications of multimedia and network resources on the higher vocational English teaching. The teacher is playing the significance role to construct environmental factors. With Internet as the carrier of the multimedia courseware, it makes teaching resources to be shared. Network can complete other teaching equipment is unable to complete strengthening teaching management to ensure that the task of communication. The applications of the combination will be researched in the future study.
\end{abstract}

\section{Introduction}

Traditional English teaching methodology is often passive listening to teach students, the classroom atmosphere dull and the language thinking but with today's information and in-depth development of education reform, multimedia technology as a new form of education and teaching method is more and more popular with the combination of English teaching more make full of individual character and the English teaching. The emergence of cloud computing for colleges and universities to establish the network teaching platform, integration of teaching resources to carry out the digital campus construction provides a new network environment and the solution. Multimedia teaching platform of research and practice in colleges and universities has very important practical and applicable significance. Multimedia teaching provides us to overcome the disadvantages in traditional teaching new ways of teaching. Use of multimedia technology which can be demonstrated in practice which is difficult to observe the experiment phenomenon and can display graphics from different perspectives which can make some abstract concepts into specific observable images, graphics, can be dynamically demonstrate some change process. In addition, the multimedia can put some change process in stages demonstration and so on. This approach could maximum limit arouse the enthusiasm of students, stimulate students' interest in learning and can fully show the teaching content to the point which break through the difficulty and guide students to actively explore and active learning by means of video or animation show its process. Moreover, the method and can successfully guide the student to break through the thinking obstacles and make originally difficult teaching activities are full of charm and which effectively stimulate students' interest in learning [1-2].

The English program aims to develop integrated linguistic skills, with an emphasis on listening comprehension and oral production and a focus on learning for authentic communication. The use of the development of education and education media are inseparable. With the laws of education itself, the research achievements of cognitive psychology, artists, system creative personnel of creative labor and comprehensive and rapid development of modern science and technology of interactive multimedia English teaching system has been on our traditional education brings strong shock wave. A great transformation of education has been in the making.

In this paper, we research on the applications of multimedia and network resources on the higher vocational English teaching. The freedom of the development of network technology, multimedia information transmission will make and enable the education all over the world exchange, sharing possible. With Internet as the carrier of the multimedia courseware, it makes teaching resources to be 
shared. Network can complete other teaching equipment is unable to complete strengthening teaching management to ensure that the task of communication between teachers and students. In network teaching environment, teachers can make use of the network broadcast function to finish the class collective teaching also can be operated by point to point communication with students according to different levels of students of different learning content and the implementation of targeted tutoring form a group teaching pattern. Using the computer storage and calls the function, the teacher can show up in class and the class teaching content related to all kinds of information, images, sound which will largely help students to master and understand the contents of the textbooks or the forefront of this discipline knowledge and material which will be discussed below.

\section{The Proposed Approach and Methodology}

The multimedia and network resources overall design are shown in figure 1 below, the whole system can be divided into four parts: content acquisition, production and management section (CMS), data service center, wireless networks and wireless devices. Content management part in charge of multimedia audio and video data recording, storage and management; Data service center is responsible for communicate with wireless terminals and receives a command Request terminal equipment, after processing to give Response; Wireless network provides the network transmission medium; Wireless terminal equipment work is through the wireless network environment and real-time interactive communication, data center and real-time processing in the wireless network for multimedia data.

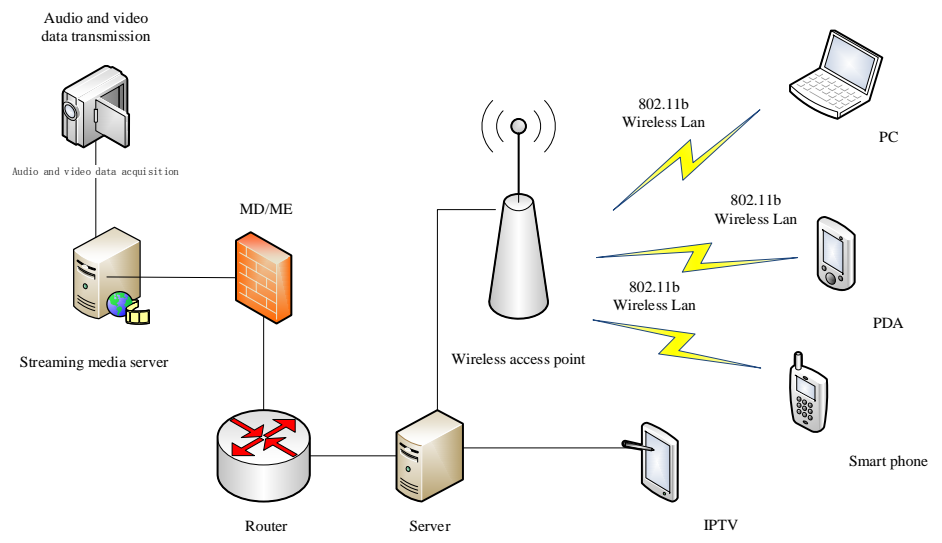

Figure 1. The architecture technology for multimedia and modern network

Interactive multimedia system for network interaction in the first place, doing the underlying transport interface definition, this paper shows how to use the underlying network communication protocol for data transmission; For the interpretation of the information transmission platform, illustrates the application of how messages transmitted the information transmission platform. Application platform need to provide services to meet the needs in the platform for secondary development, this article lists the three kinds of upper provide public services, to facilitate the management and development of application. An interactive multimedia network teaching system must have a specific application to complete the teaching process.

\section{The Principles of English Education}

The teacher is playing the significance role to construct environmental factors. Play the role of the helper, facilitator rather than the imparter of knowledge and implants the main body of students is to construct knowledge. They have a motivation for their own learning, building, cumulative, goal guidance, diagnostic and other characteristics necessary. Constructivism theory attaches great importance to the study of the collaborative and interactive with students as the center in a real scenario implementation knowledge construction. Because of the multimedia computer and network communication technology based on Internet is particularly suited to the characteristics of constructivism learning environment. Therefore it can be used as an ideal cognitive tool of 
constructivism learning environment. The method will effectively promote and enhance students' cognitive development and improve the ability of autonomous learning. Multimedia technology as graphics, images, voice, text, video and other information in the form of a highly integrated can give learners to provide a variety of information input simultaneously. Multimedia is the most can reflect student centered language learning mode of teaching techniques. It provides the students' autonomous learning with unprecedented reliable platform.

Traditional English teaching mainly focus on teachers who give priority to with the teaching material, teacher's knowledge and ability is limited, however, even some teachers' teaching content is to imitate the teaching material completely from the book. Therefore, the traditional teaching mode is difficult to achieve the requirements of a large amount of language input. The development of modern information technology especially the development of network technology provides teachers with a very broad space. Teachers can use multimedia technology. Teachers provide the student with the abundant teaching resources. Fundamentally improve the teaching efficiency will make up for the deficiency of the traditional teaching mode.

Using the microcomputer technology can be easily implemented simulation reality and even the experiment of simulation in reality is difficult to achieve. If, however, is keen on simulation on computer operation and ignore the student's actual operation, is bound to go against the cultivation of the student beginning ability. Simulation experiment is not true, at the same time makes its credibility is not high, if to ask students to accept the information they had suspected for a long time and that will make them lose question, innovative desire and ability to return to the path of mechanical and mechanical memory, with the intention of using multimedia computer assisted instruction. Teaching activity, it is necessary to exert the principal role of students. The traditional teaching is a teacher by simple blackboard writing, languages, books and other media to teach students knowledge, students by watching, listening writing and so on passively accepting knowledge. This boring way and not be able to speak the information displayed in the form of dynamic, rich, such not only inefficient, but also the students' ability of seldom is hamstrung by a. In such a situation, more and more education workers have realized the important role of multimedia in the teaching. The roles of multimedia auxiliary teaching lies in the applications of modern technology and stimulates and arouse the enthusiasm of students, inspire the thinking of students, cultivate the students' found the problem, thinking, problem solving skills. Therefore, in the application of multimedia in the teaching practice, we must pay attention to not allow the audiovisual education media from students to explore, analysis, thinking of the time which must be the cultivation of students' thinking ability as an important goal of teaching [3-5].

\section{The Core Techniques of Multimedia and Network Education.}

In the English classroom for teaching, multimedia technology is playing a more and more important and even indispensable role. Multimedia technology refers to a kind of the text, images, sound, and other forms of information together through the computer integrated treatment and control. Effective use of multimedia courseware in English teaching, make full use of the perceptual materials combined with the student's image thinking. The best situation is a good visual and auditory impact which can arouse the enthusiasm of the students. Keep and lasting memory is beneficial to the students' knowledge to get the best teaching effect. To train students fluent in a foreign language, we must first let students practice for a large number of material supporters. Have expert analysis the traditional English teaching method is basically a failure. The deep-rooted traditional method, it is difficult to out. China's present situation of English learning is the teacher with the traditional teaching method with the group after group of students in a traditional way. Oral English, most of the teachers listen to mention and daunting, let alone a student. Vivid language environment conducive to language acquisition but the traditional pattern of classroom teaching provides such ideal language environment. Voice laboratory based on modern multimedia technology by creating teaching situation. Conform to the characteristics of language teaching. In the following figure 2, we show the general application of multimedia based teaching pattern. 


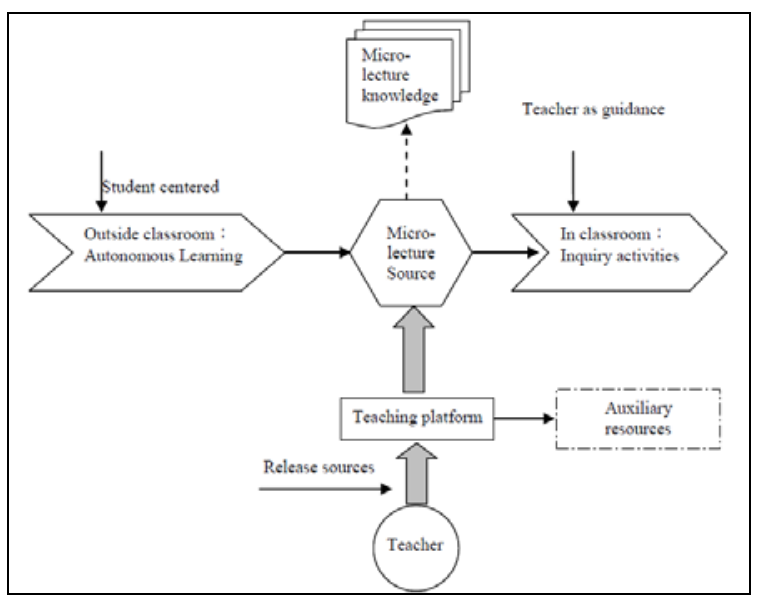

Fig. 2 The General Application of Multimedia based Teaching Pattern

Media is the interpersonal information communication of mediation and in simple terms, is the carrier of information which is also known as the medium. Multimedia is the meaning of multiple media, is directly impact on the senses of a variety of media. When students learn English learning as a pleasant enjoyment and is no longer a burden, nature is more conducive to promoting learning transfer. The teacher can't refer to the different characteristics of each student and carry on the effective training in pronunciation and intonation. Using the new multimedia teaching equipment, the teachers at any time to listen to the voice of any one of the students in the classroom, to each student's pronunciation and intonation targeted individual guidance and correct. Greatly improve the English listening teaching effect. With the rapid development of science and technology, video has become people to communicate and transfer information of one of the most important means. The students' interest in learning is they seek knowledge actively consciousness tendency and rich expressive force by using the multimedia teaching can fully arouse the enthusiasm of students which will attract the students attention and alleviate fatigue when listening to lectures and the student can accept knowledge through various channels denoted diversified.

Combination of Teaching with Multimedia. As is known to all, language teaching has strong practicality and teachers can use multimedia to the teaching content of the special language. Multimedia teaching can combine several big aspects in their English study effectively in colorful language background let students experience the fun of learning comes from real pure pronunciation intonation on the network and assimilation and for most of the students like to influence the student's ability of language use is subtle which will greatly enhanced the confidence of the students to learn English. In the following figure 3, we show the sample combination of the teaching with media.

\section{Cllodule 2 UNIT 1 lesson 3}

Choose your section:

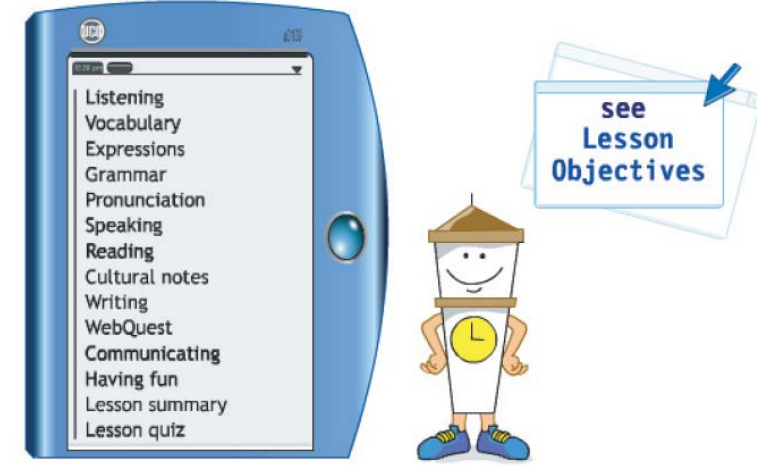

Fig. 3 The Sample Combination of the Teaching with Media 


\section{Conclusion and Summary}

In this paper, we research on the applications of multimedia and network resources on the higher vocational English teaching. Multimedia teaching platform of research and practice in colleges and universities has very important practical and applicable significance. Multimedia teaching provides us to overcome the disadvantages in traditional teaching new ways of teaching. The best situation is a good visual and auditory impact which can arouse the enthusiasm of the students. Keep and lasting memory is beneficial to the students' knowledge to get the best teaching effect. In the future, we plan to combine more related multimedia technologies to polish and modify the current pattern.

\section{References}

[1] Chun-lin, L., \& Academy, G. P. (2014). A study on integration of task-based approach with process-oriented assessment in college english teaching - taking higher vocational college English teaching as an example. Journal of Guangxi Police Academy.

[2] Magli, E., \& Frossard, P. (2009, June). An overview of network coding for multimedia streaming. In Multimedia and Expo, 2009. ICME 2009. IEEE International Conference on (pp. 1488-1491). IEEE.

[3] Xiao-rui, W., Xin-hua, Y., \& College, L. T. (2014). On integration of information technology application and higher vocational English teaching mode. Journal of Lianyungang Technical College.

[4] Haiying, H. (2014). Situation and countermeasures of higher vocational college international professional english writing teaching. Journal of Educational Institute of Jilin Province.

[5] Liang, Z. (2014). On tutoring and teaching based on the theory of constructivism - taking higher vocational colleges' English speaking competition as an example. Journal of Minxi Vocational \& Technical College.

[6] Sharif, A., Potdar, V., \& Chang, E. (2009, June). Wireless multimedia sensor network technology: A survey. In Industrial informatics, 2009. INDIN 2009. 7th IEEE international conference on (pp. 606-613). IEEE.

[7] Liqin, T. (2014). Study on the present situation and countermeasures of humanities cultivation in higher vocational school English teaching: taking higher vocational English in the construction school for example. Science Education Article Collects. 